\title{
Dona Flor e seus dois maridos e a recepção histórica da crítica Dona Flor e seus dois
} maridos and the historical reception of criticism

Regina Gomes ${ }^{1}$

\footnotetext{
'Doutora em ciências da comunicação pela Universidade Nova de Lisboa, especialidade de cinema, professora do curso de comunicação social e do Programa de Pós-Graduação em Comunicação e Cultura Contemporâneas da Universidade Federal da Bahia (PósCom/UFBA). E-mail: reginagomesbr@gmail.com
}

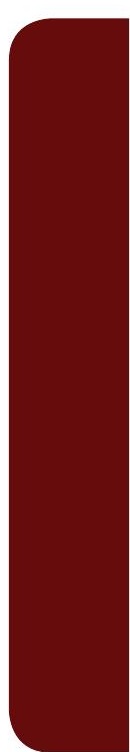


Resumo: o presente artigo tem por objetivo central analisar textos da crítica (nacional e internacional) do filme Dona Flor seus dois maridos, publicados na seção "Dossiês críticos" da revista brasileira Filme Cultura em 1979. O filme, campeão de bilheteria, dividiu opiniões e gerou uma série de comentários sobre os rumos que o cinema brasileiro deveria tomar a partir dali. O exame dos textos leva em consideração a crítica como instância de recepção histórica da obra cinematográfica e o crítico como leitor particular de seu tempo.

Palavras-chave: Dona Flor e seus dois maridos; recepção; crítica de cinema.

Abstract: this article aims to analyze film reviews (national and international) of the Dona Flor e seus dois maridos published in Dossiês Críticos section of the Brazilian magazine Filme Cultura in 1979. The film, box office champion, divided opinions and generated a number of comments on what direction the Brazilian Cinema should take from there. The examination of the texts takes into account the criticism as instance of historical reception of the cinematographic work and the critic like private reader of his time.

Keywords: Dona Flor e seus dois maridos; reception; film criticism. 


\section{Introdução}

Em sua recente visita ao Brasil, Antoine de Baecque (2014) fez uma provocação quanto à legitimidade e credibilidade da crítica de cinema contemporânea, afirmando que "é tão importante escrever sobre um filme quanto realizá-lo". A tarefa diária de apreciação de filmes tem se configurado, embora com a sombra da imagem de crise, como uma importante e indissociável atividade ligada a experiência do cinema.

Com efeito, pensamos que a crítica de cinema é parte integrante e fundamental daquilo que chamamos de "experiência fílmica", e o pensar, falar, escrever sobre filmes denota traços receptivos que ficam gravados na pele dos textos. Consideramos aqui que esses traços, resíduos de uma experiência do crítico com o filme, expressam canais de recepção de uma obra. É certo que se trata de um canal receptivo específico, afinal o crítico é um espectador habilidoso e atento, mas nem por isso deixa de assumir a condição de espectador que, a um só tempo, frui os filmes, pensa e escreve sobre eles.

Este artigo se propõe a analisar os textos críticos sobre o filme Dona Flor e seus dois maridos publicados na década de 1970, na revista brasileira Filme Cultura. São críticas exibidas em jornais nacionais e internacionais, compiladas em forma de dossiê, e nosso objetivo será iluminar esses textos por meio de um exame que considere os condicionantes históricos motivadores da recepção da obra de Bruno Barreto. Nosso problema diz respeito à razão pela qual Dona Flor teve uma recepção crítica constituída por controvérsias levadas às páginas da imprensa brasileira e estrangeira, e como as configurações estético-históricas moldaram o cenário de disputas discursivas da época.

Para isso, apoiamo-nos em uma pesquisa bibliográfica fundada na estética da recepção de Hans Robert Jauss (1979, 1994) e nos estudos históricos de recepção nos media de Janet Staiger (1992, 2000, 2005). Ambos os autores ressaltam a importância dos elementos históricos que compõem a ideia de recepção de uma obra artística e de como a crítica possui um papel basilar para investigar essa experiência receptiva.

\section{Breves considerações sobre os estudos de recepção e crítica}

Antes mesmo do cinema, a preocupação com os estudos sobre recepção estética nas obras de arte ganha relevância notadamente no campo literário com a Escola de Konstanz, e é Hans Robert Jauss (1979; 1994), um dos pioneiros da estética da recepção, quem direcionará críticas às análises meramente textuais, propondo 
refletir sobre a historicidade das obras literárias, fruto das múltiplas interpretações dos leitores ao longo do tempo. Conforme a estética da recepção, a obra só existe porque é lida. Não há história da literatura (ou de qualquer outra arte) sem uma história da recepção das obras.

Buscando romper com a fratura entre a história da literatura e a estética, e colocando o leitor numa posição privilegiada, Jauss (1994), em História da literatura como provocação à teoria literária, divide seu projeto em sete teses e já na primeira afirma:

\begin{abstract}
A história da literatura é um processo de recepção e produção estética que se realiza na atualização dos textos literários por parte do leitor que os recebe, do escritor, que se faz novamente produtor, e do crítico, que sobre eles reflete. (p. 25)
\end{abstract}

Desse modo, ele considera a historicidade como motor de atualização da obra, porquanto esta é sempre fruto de camadas de leituras diversas agindo contra seu enrijecimento e demonstrando sua vivacidade.

Não por contingência, a estética da recepção joga luz sobre o lugar da crítica. Esta, como parte constituinte do processo de atualização dos textos artísticos, indica que a apreciação dos atos de leitura ali inscritos é, a um só tempo, necessária e essencial para o que chamamos de estudos de recepção no cinema. Os juízos acumulados da crítica, aliados a juízos de outros agentes, como os dos leitores, formam uma camada de sentido que é historicamente atualizada em sua recepção e traduzem um conjunto de atividades interpretativas que se revigoram no tempo.

Importa aqui pensar os textos da crítica de cinema como vestígios de recepção e verdadeiros testemunhos dos sentidos conferidos aos filmes. Refletir, sobretudo, em como a recepção é marcada pelo contexto sociocultural, pelas configurações históricas que, em alguns casos, sobredeterminam as respostas da crítica.

Vale destacar que a estética da recepção literária exerceu forte influência sobre estudos em outros campos artísticos, particularmente no cinema. Robert Stam (2003) e David Bordwell (1991) contextualizam os anos 1980 e 1990 como uma fase de crescente interesse pelo receptor e pela relação dialógica deste com o filme, afirmando que tal interesse foi influenciado pelas teorias da recepção na literatura, especialmente aquelas agregadas à recepção estética de Jauss. Ambos reafirmam o papel ativo do espectador e asseguram que a história do cinema não é somente a história dos filmes, mas a história dos múltiplos significados que os públicos têm atribuído a eles.

A natureza socialmente condicionada da espectatorialidade também pode ser vista nos trabalhos de Janet Staiger (1992, 2000, 2005), que desenvolve uma 
abordagem histórico-materialista a partir do que se denomina por "estudos históricos de recepção nos media”, cujo objetivo central é compreender historicamente as atividades interpretativas de espectadores de cinema. Essas investigações se inserem temporalmente em fins dos anos 1980, quando se verifica a ascensão das teorias que se debruçam não apenas sobre os efeitos textuais, mas sobre o momento de recepção da obra fílmica como lugar de convergência entre texto, espectador e contexto. Staiger - crítica incisiva da análise meramente imanentista - vai além dos limites dos filmes e utiliza críticas, contratos legais, revistas especializadas, manuais, comentários de fãs e até mesmo "cartões escolares de pontuação para classificação de filmes", que podem ser excelentes fontes para reconstruir estratégias interpretativas e respostas do público de um dado horizonte histórico.

Coautora da obra The classical Hollywood cinema, junto com David Bordwell e Kristin Thompson (1986), Staiger adere ao que ficou conhecido como estilística histórica, investigando o cinema clássico americano e seu modo de produção. Já em Perverse spectator (2000), Staiger reúne ensaios que tratam da multiplicidade identitária do espectador, cujo processo de recepção deve ser analisado em função de seus condicionantes históricos. Apresentando estudos de caso como o de Laranja mecânica (Stanley Kubrick, 1971), a autora parte das críticas do filme e chega a três vetores discursivos básicos: no primeiro, os textos críticos que envolveram a representação da violência; no segundo, as questões morais e políticas que circundavam o filme de Kubrick; e no terceiro aponta para as questões de gênero identificadas, sobretudo, nos conceitos de "obscenidade" e "pornografia”.

Para Staiger, o debate público causado pelo filme no momento em que fora lançado sinalizou a pista para a compreensão dos objetivos de seu empreendimento metodológico:

O que eu pretendo fazer aqui é o que eu chamo de estudos históricos da recepção. Esta pesquisa pretende iluminar os significados culturais de textos em uma época e em circunstâncias sociais específicas para espectadores específicos, e pretende contribuir com as discussões acerca dos efeitos espectatoriais de filmes ao ir além das análises centradas no texto. (2000, p. 162, tradução nossa) ${ }^{2}$

Enfim, tal como Staiger, buscamos no presente artigo nos afastar de uma metodologia essencialmente presa às análises internas - o que reduziria o

\footnotetext{
${ }^{2}$ Do original: "What I shall be doing here is what I call historical reception studies. This research attempts to illuminate the cultural meanings of texts in specific times and social circumstances to specific viewers and it attempts to contribute to discussions about the spectatorial effects of films by moving beyond text-centered analyses".
} 
horizonte interpretativo do leitor - e considerar a tese de que não apenas os filmes, mas os textos escritos sobre eles conformam-se como um lugar enriquecedor para pensar a recepção histórica das obras.

Filmes polêmicos trazem consigo um conjunto de resíduos de experiências, facilitando o trabalho do pesquisador, que irá dispor de um rico material para examinar a recepção da obra. Foi o caso de Dona Flor e seus dois maridos, dirigido pelo então jovem cineasta de 21 anos, Bruno Barreto, em 1976. Bem recebido pelo público - tornou-se uma das maiores bilheterias da história do cinema brasileiro -, a película protagonizada por Sônia Braga, José Wilker e Mauro Mendonça gerou controvérsias e dissenso entre a crítica produzida no país e no estrangeiro.

\section{A revista Filme Cultura e o dossiê sobre Dona Flor e seus dois maridos}

A revista Filme Cultura (1966-1988) nos deixou um grande legado histórico. Trata-se de um conjunto de textos, sobretudo sobre cinema brasileiro, que dialogava abertamente com sua época, representando um rico acervo de atos cinematográficos de leitura e recepção. Os discursos da crítica ali encontrados são excelentes registros de práticas interpretativas, que dizem muito sobre um certo tipo de recepção que filmes brasileiros das décadas de 1970 e 1980 tiveram.

Uma das mais longevas revistas sobre cinema no país, Filme Cultura parou de circular no final da década de 1980 e foi editada pelo Instituto Nacional de Cinema Educativo (INCE), pelo Instituto Nacional de Cinema (INC) e, por fim, pela Embrafilme e Fundação do Cinema Brasileiro (FCB). Teve nomes de destaque entre seus colaboradores, como Antônio Moniz Vianna, Paulo Emílio Salles Gomes, Ely Azeredo, José Carlos Avellar e Jean-Claude Bernardet. Sem dúvida, um periódico de grande valor para aqueles que pensavam em um projeto para o cinema nacional.

Depois de dezenove anos fora de circulação, o Centro Técnico Audiovisual (CTAv) lançou, em 2007, a edição especial n ${ }^{\circ} 49$ da Filme Cultura, comemorativa dos 70 anos do INCE. Em abril de 2010, o n 50 da revista voltou a circular regularmente com periodicidade trimestral, ainda que o projeto sofresse interrupções constantes.

A seção "Dossiês críticos", particularmente, reunia um conjunto de críticas nacionais e internacionais sobre um mesmo filme lançado, configurando uma espécie de catálogo de recepção crítica da obra. Esse rico material nos serviu aqui como fonte primária para o exame de condicionantes históricos que guiaram a acolhida do filme Dona Flor e seus dois maridos. Barreto já havia dirigido outros 
filmes ${ }^{3}$, mas foi Dona Flor que lhe deu o status de promessa para o cinema brasileiro. A repercussão nacional e internacional da obra adaptada do romance homônimo de Jorge Amado se traduziu na complexidade do debate acerca do cenário cinematográfico brasileiro e numa fragmentação entre os discursos da crítica da época.

Na edição de maio de 1979, Filme Cultura trazia 18 textos apresentados no dossiế ${ }^{4}: 16$ críticas $^{5}$ e 2 comentários, respectivamente de Jorge Amado e Leopoldo Serran, roteirista do filme.

Vale destacar que Dona Flor obteve o posto, por mais de trinta anos, do filme mais visto da história do cinema nacional desde sua estreia em 1976 (alcançou o patamar de 10,8 milhões de espectadores), posto que foi recentemente superado por Tropa de elite 2: o inimigo agora é outro (2010), de José Padilha, que obteve 11,1 milhões de espectadores, e Os 10 mandamentos (2016), de Alexandre Avancini com 11,3 milhões.

\section{A repercussão na imprensa estrangeira}

Para o crítico Angelo Selmi (Oggi), Dona Flor foi um filme que perdeu a chance de imprimir uma textura politizada à narrativa, com tons de comédia ambientada no Nordeste do Brasil. Desde o Cinema Novo, esperava-se que os filmes brasileiros acedessem ao modernismo político, já marcado por um compromisso de crítica às desigualdades regionais do país. Mas não é isso o que a imprensa, particularmente a italiana, vê em Dona Flor. Pelo contrário, alguns jornais deixavam clara a cobrança por uma narrativa mais engajada, e conforme Selmi (Oggi):

Quando falamos de cinema brasileiro, pensamos imediatamente num cinema de gênero engajado, aquele de Ruy Guerra e de Glauber Rocha, belo e difícil, com seus

\footnotetext{
${ }^{3}$ Respectivamente seus primeiro e segundo longas Tati, a garota (1972) e A estrela sobe (1974).

${ }^{4} U m$ detalhe que nos chamou atenção e merece ser mencionado foram os textos não datados. Como sabemos que o filme foi lançado em 1976 e a revista publicada em 1979, arriscamos supor que os textos foram publicados entre 1976 e 1977, auge do período de seu lançamento.

${ }^{5} \mathrm{O}$ dossiê foi composto pelas seguintes críticas internacionais: Samba cinematográfico (Albert Cervoni, L'Humanité, Paris), Irresistivel (Michel Mohrt, Le Figaro, Paris), A restauração (II Giorno, Roma), Habilmente tramado (Angelo Selmi, Oggi, Roma), Alegria de Viver (Giovanni Grazinni, Corriere della Sera, Roma), Duas leituras (U. BZ., La Stampa, Roma), Resultado irregular (Henry Segura, Cinemateca, Montividéu), Tom inseguro (Janet Maslin, The New York Times, Nova Iorque). As críticas nacionais: Ternura e ironia (Ivo Egon Stigger, Correio do Povo, Porto Alegre), Meio Termo (Rogério Menezes, A Tarde, Salvador), Sucesso planejado (Edmar Pereira, Jornal da Tarde, São Paulo), Ampliação do público (Ely Azeredo, Jornal do Brasil, Rio de Janeiro), Fluência de linguagem (Nelson Hoineff, Última Hora, Rio de Janeiro), Toque de classe (Valério Andrade, Manchete, Rio de Janeiro), O contador de histórias (José Carlos Avellar, Jornal do Brasil, Rio de Janeiro), O profissionalismo (Fernando Ferreira, O Globo, Rio de Janeiro). As oito críticas internacionais foram trazidas por Sérvulo Siqueira.
} 
problemas do Nordeste; mas, desta vez, estamos diante de uma obra descompromissada e picaresca, ambientada na Bahia e extraída de um romance do venerável Jorge Amado, escritor-monumento nacional, depois de ter sido algum tempo deputado comunista (2010, p. 244).

Se o Brasil já oferecera ao mundo primorosos libelos políticos de Rocha e Guerra, agora Barreto nos apresenta "um filme ligeiro, desbocado e fantasioso" e cuja censura passou ao largo, já que "não há ideologicamente nada de suspeito", afirmou o crítico U.Bz., do La Stampa (2010, p. 245). De fato, as cenas picantes de Dona Flor foram negligenciadas pelos censores, e vale lembrar que durante a ditadura militar no Brasil o Estado dá novo impulso à indústria cinematográfica (torna-se uma espécie de patrono do capital cultural brasileiro, como bem desenhou Renato Ortiz em A moderna tradição brasileira). Através da Embrafilme, aglomera funções nas áreas de coprodução, fiscalização, distribuição, exibição e divulgação (inclui-se aí o financiamento da própria revista Filme Cultura). Filmes como Dona Flor, Xica da Silva (1976), de Cacá Diegues, e Tenda dos milagres (1977), de Nelson Pereira dos Santos, representaram de certo modo esse desejo de afastamento de um projeto que envolvesse necessariamente uma bandeira ideológica.

Segundo Ballerini (2012), no mesmo período "Cerca de cinco filmes ultrapassaram a marca dos três milhões de espectadores: Dona Flor e seus dois maridos (1976) atingiu a impressionante marca de 10,8 milhões de espectadores, seguido por A dama do Lotação (1982) - 6,5 milhões - e Lúcio Flávio, o passageiro da agonia (1977) - 5,4 milhões [...]" (p. 32). Como se pode concluir, o cinema brasileiro encampava o projeto do nacional popular e deixava de lado, pelo menos para a crítica, o projeto anterior inspirado no modernismo político-estético.

Por outro lado, uma parte da crítica internacional reconhecia na obra-fonte de Jorge Amado um teor de crítica ao comportamento da pequena burguesia baiana, traduzida por Barreto para as telas de cinema, sobretudo nos personagens de Flor, Vadinho e Cazuza Funil, que representavam aquela burguesia machista, “mesquinha e bisbilhoteira, beata e formalista”, aponta U.Bz (2010, p. 245). Henry Segura, da Cinemateca (2010, p. 245), afirma que "De certa forma, o espírito transmitido por Jorge Amado é respeitado no filme”.

Mas nem todos pensavam assim. Os críticos estrangeiros também não deixaram de mencionar que essa sátira pequeno-burguesa vem acompanhada por um tom "pitoresco" e "exótico", imagem cristalizada pela lente estrangeira de um país cujo filme foi comparado a um "belo samba cinematográfico”, conforme Albert Cervoni, do L'Humanité (2010, p. 242). 
Com efeito, o olhar sobre o cinema brasileiro era visto como o olhar sobre o próprio país, ou seja, um misto de exotismo e folclore que o Cinema Novo tentara romper nos anos 1960, mas que agora filmes como Dona Flor o faziam retornar. Para o crítico Michel Mohrt, do Le Figaro (2010, p. 242): “Somente no Brasil, terra de encantamentos e feitiçarias, onde a religião católica vive em boa harmonia com o vudu, é que tais aventuras são possíveis". Bruno Barreto proporcionou "aos apreciadores uma pequena viagem de prazer ao Brasil. Não ao duro Brasil do Cinema Novo, mas àquela quintessência da imagem alegre que é a Bahia, onde o povo e a burguesia se liberam de inibições e medos num jogo fantástico e malicioso", atesta U. Bz do La Stampa (2010, p. 245).

Ora, temos aqui elementos de que a crítica estrangeira de Dona Flor leu o filme de Barreto, e de resto todo o Brasil, como um espaço de exotismo e erotismo, sobretudo o encarnado por Sônia Braga, deixando clara a rigidez dos estereótipos como grandes marcadores culturais da época, ainda que hoje essa imagem, de certo modo, permaneça. Conforme Staiger (1992), a leitura resultante da relação entre críticos e filmes seria predeterminada por condicionantes sociais e culturais, resultando, portanto, em distintos modos de recepção.

É certo que essa lente exótica venha carregada de pílulas de confetes, sendo que o filme igualmente foi visto como possuidor de trama e ritmo hábeis, "simpaticamente ligeiro, brincalhão e inteligente", demonstrando a "alegria de viver" do brasileiro, assegura Granzinni, no Corriere della Sera (2010, p. 244).

Mas foi a curiosa ideia de "restauração", do fim ou morte do Cinema Novo e do retorno a um modo de produção que se aproximava das chanchadas, que a crítica italiana prenunciava: "O que restou dos velhos temas do sertão caros ao Cinema Novos? Praticamente nada”, responde o crítico do II Giorno (2010, p. 243), e nem o fato de Bruno Barreto ser filho de um grande produtor e participante do movimento (Luis Carlos Barreto) fez com que a crítica entrevisse outra resposta, afinal, se nos últimos anos ocorreram significativas transformações no panorama político do país,

era lógico que também mudasse o cinematográfico. Voltaram à moda as chanchadas, a comédia popular dos anos 40 e 50 , construída sobre canções (e em Dona Flor, a música de Chico Buarque merece uma menção especial), atualizada por um tom desabusado e um pouco de sexo. (2010, p. 243)

Aqui vale uma reflexão sobre a recepção do Cinema Novo na Europa e o desapontamento da crítica com os rumos tomados pelo cinema brasileiro a partir da década de 1970. Figueirôa (2004) e Gomes (2015) já caracterizaram, respectivamente 
na França e em Portugal, a má acolhida de filmes brasileiros após a fase áurea do Cinema Novo, transformado em modelo e paradigma de qualquer cinema que viesse do Brasil. A crítica francesa e portuguesa encarnava o projeto de produção de um cinema de expressão autoral que valorizasse o primado estético, mas também o político, ou seja, o cinema como arte autoral engajada.

Partilhando a mesma aversão pelo cinema popular-comercial, a crítica portuguesa e francesa abriu-se a novas cinematografias modernas e desempenhou um papel considerável na aceitação e promoção do cinema de arte e experimentação. Foi nos anos 1960 que a crítica mais sustentou e alimentou a artisticidade do cinema, visto até então, pela maioria dos espectadores, como mera distração. A instauração de um cinema moderno punha em xeque o critério de continuidade clássica calcada em grandes campanhas de marketing e revelava seu descompromisso com a linguagem oficial e com a lógica linear.

Nada disso parecia definir os novos filmes brasileiros Dona Flor, Xica da Silva, Lúcio Flávio ou A dama do Lotação, pelo contrário, essas películas representavam agora a diversidade de tendências e gêneros, e a nítida aproximação com o mercado.

Para Jauss (1994), a recepção é sempre um fato social, de tal modo que a obra não pode se apresentar como absoluta novidade, vez que ela sempre se relacionará com o público por meio de marcadores socioculturais já conhecidos. Assim, cobravase nas críticas à Dona Flor o “respeito" pelo legado da estética cinemanovista, atitude que dialogou com o quadro contextual reativo às novas cinematografias brasileiras do período. O que estava em causa, na verdade, era o modelo de produção estética e econômica desses novos filmes que a crítica europeia se recusava a abraçar.

\section{A recepção entre os críticos brasileiros}

Já o exame da recepção do filme pela crítica brasileira nos guia para a recorrência de certos aspectos, também ditos como marcas de época, que nos revela um cenário de divisão, às vezes de polarização de opiniões, ou uma fragmentação ideológica da esquerda visível nos discursos da crítica de cinema no período ${ }^{6}$. Desde a sua estreia, Dona Flor causou controvérsias, mas Barreto não encampava sozinho esse projeto. Em consequência do processo de industrialização da produção cultural brasileira, entre meados dos anos 1970 e fins dos 1980, alçado anacronicamente por um Estado militar e autoritário, o cinema brasileiro se volta para o mercado e expande

${ }^{6}$ Margarida Maria Adamatti (2016) igualmente examinou a recepção crítica do filme Xica da Silva de Carlos Diegues (1976), sobretudo o debate causado pelo filme no jornal Opinião. 
sua produção bastante diversificada na época (filmes históricos, pornochanchadas, comédias despretensiosas, melodramas, policial-político etc.).

Antigos e novos realizadores buscavam a aproximação com o público e defendiam a bandeira mercadológica do cinema, gerando polêmicas nos jornais e forjando um tipo de recepção calcada no confronto de ideias. Atento, Rogério Menezes, do A Tarde, afirma que:

\begin{abstract}
Mais importante do que analisar isoladamente o filme de Barreto é discutir toda uma série de comentários que o filme gerou e os questionáveis efeitos positivos do filme em relação ao cinema nacional. A reação das pessoas ao filme foi das mais variadas. A posição dos críticos também. André Setaro, na Tribuna da Bahia, chamou Dona Flor de "telenovela de 1984". Inimá Simões, do Movimento, questionou a participação musical de Chico Buarque num filme desses. Em compensação, Jairo Arco e Flexa, de Veja, elogiou-o profundamente. Em termos de público, as opiniões variaram muito: "uma pornochanchada bem feita". "Mais um filme comercial". "Um abacaxi enrolado em papel de presente". "A melhor coisa que o cinema brasileiro já fez". "Não pensei que o cinema nacional fosse capaz de fazer um filme assim". "Ah, esse é o filme nacional que a gente não se arrepende de ter assistido". O que se constata muito, nessas opiniões, é um radicalismo exagerado; ou se gosta ou se odeia. Talvez o certo fosse meter a coluna do meio, pois Dona Flor trouxe vantagens e desvantagens para o cinema brasileiro. Dona Flor é um filme extremamente contraditório. (2010, p. 247)
\end{abstract}

Se o crítico Rogério Menezes colocou Dona Flor como "um filme extremamente contraditório", essa mesma contradição se mostrava visível nos discursos sobre ele. Edmar Pereira, do Jornal da Tarde (2010, p. 248), fala em "sucesso planejado" e questiona: "Um caminho novo para o cinema brasileiro? Um grande espetáculo popular? Uma produção orquestrada seguindo o mais alto padrão possível de profissionalismo? A resposta só poderia ser sim”.

As disputas discursivas internas muitas vezes geravam um tipo de desvio analítico em que os aspectos expressivos do filme, como o roteiro ou a montagem, eram negligenciados em razão de um debate ideológico sobre o mercado, sempre presente na cena cinematográfica nacional. Ely Azeredo, no Jornal do Brasil (2010, p. 249), sinaliza que "Um quarto de hora de projeção basta para expor o mecanismo mercantil do empreendimento" e destaca o slogan publicitário do filme na época: "um filme brasileiro de padrão internacional".

De fato, muitos críticos mencionaram o modelo de internacionalização do produto, ou seja, "Um filme de equipe, com boa história, bons técnicos, atores famosos e competentes, um diretor de comprovada capacidade, que submete seu 
talento a uma concepção de cinema ou, melhor ainda, a uma opção", assinala Edmar Pereira, no Jornal da Tarde (2010, p. 248). A polarização da recepção crítica se funda particularmente no debate sobre a melhor opção para constituir uma cinematografia brasileira: abrir estradas para uma estrutura "industrial”, viável e autossustentável, e consequentemente reconquistar o mercado, ou manter-se afastado dessa estrutura e defender um cinema de expressão nacional, político e inventivo.

Para Staiger (1992), é necessário fazer uma compreensão histórica das atividades interpretativas mais do que tão somente uma interpretação dos filmes, traçando, desse modo, um limite entre os estudos de textos e de recepção. Estes se propõem a refletir sobre os atos de leitura e por que eles são conformados historicamente. No Brasil, o debate interpretativo se dava na arena pública do jornalismo cinematográfico e certamente moldou a recepção da crítica aos filmes brasileiros da segunda metade da década de 1970.

Nelson Hoineff, no Última Hora (2010, p. 249), destacou-se, na outra ponta do cabo, na defesa incondicional do filme, e argumenta que Dona Flor, "mais que nenhum outro filme moderno, ensina o cinema brasileiro a falar”. E Edmar Pereira (2010, p. 248) acrescenta, ao dizer que Dona Flor se apresenta "De forma clara, direta, perfeitamente compreensível por qualquer tipo de espectador". A pró-comunicação com os espectadores, realizada através de uma narrativa acessível, foi quase uma conciliação entre o espetáculo que se propõe artístico e a necessidade de vencer a resistência do público com o cinema brasileiro. Crítico consagrado do Jornal do Brasil, José Carlos Avellar (2010, p. 250) também se manifestou e resume com propriedade o mérito de Barreto para "contar uma história":

Trata-se só de incorporar certos valores da narrativa popular a um sistema de muitos bons modos - o estilo de narrar do filme americano - e de fazê-lo com gestos largos, exagerados às vezes (como a repetição dos movimentos do zoom, porque se persegue talvez isso mesmo, a maneira de contar deve se sobrepor à história que se conta. [...] O espectador se encontra, então, diante de uma conversa, feita numa linguagem que lhe é familiar, e não importa que ele não saiba identificar este fato, ou fazer uma análise dessa linguagem. O que importa é o resultado prático, o espectador acompanha a narração sem qualquer esforço, ele se reconhece na tela. (p. 250)

O próprio Jorge Amado saiu em defesa do trabalho de adaptação, para ele encarado como uma recriação: "Acho o filme belo e denso, creio que está à altura das melhores criações do cinema nacional” (2010, p. 252). 
Chama atenção o fato de a crítica viver um impasse; ainda que aceitasse certos termos daquele cinema conformista e da necessidade urgente de falar com o público, continuava insatisfeita com sua estética, que nada tinha de original ou singular. Pelo contrário, o filme assentava-se na afirmação da técnica e da mentalidade profissional. A recepção da crítica traduzia, assim, a concepção de um projeto nacional popular para o cinema brasileiro defendido por alguns cineastas e intelectuais, sobretudo Carlos Diegues, com base na articulação entre a democratização do acesso consciente aos filmes e a defesa da ocupação do mercado, sem resvalar para a urgência de um modelo econômico capaz de interferir no processo criativo das obras.

O fato é que nunca foi tão evidente nesse período o termo "patrulhas ideológicas”, inventado por Diegues em 1978, que, conforme Margarida Adamatti (2016, p. 1), seria “uma ‘polícia ideológica’ [da crítica] encarregada de vigiar a produção dos artistas e de submeter a arte aos imperativos políticos". Não por acaso três das críticas direcionadas à Dona Flor também mencionavam Xica da Silva como obra da mesma safra e com os mesmos problemas do filme de Barreto.

Adamatti (2016) salienta, após analisar o caso de Xica da Silva, que a crítica de cinema se tornou uma janela por onde passava "uma das maiores polêmicas culturais entre artistas e intelectuais de esquerda no final da década de setenta” (p. 2). Com efeito, sobretudo nas publicações de esquerda, uma divisão intestina ancorava-se no entendimento do que seria de fato uma "arte engajada" a serviço do povo. E, assim como Xica da Silva, Dona Flor enfrentou essa fissura discursiva no interior dos debates da crítica de esquerda brasileira.

A espetacularização vista em Dona Flor e questionada pela crítica nacional foi atravessada por temas recorrentes e sintomáticos: 1) o orçamento de Dona Flor, que custou 5,5 milhões de cruzeiros, o que correspondia a quase dez vezes o orçamento médio da época, equivalente a Cr\$600 mil. Salienta-se o fato de o filme ter tido cinco mil figurantes; 2) sua grandiosa campanha de divulgação, com ambições internacionais - a película foi distribuída não só pela Embrafilme como também pela Paramount e Warner Bros; 3) possuir um elenco de estrelas, composto por atores egressos da televisão num período em que as telenovelas alcançavam elevadas audiências.

Esses dados demonstram, além do elevado investimento feito por Barreto, o recado dirigido ao cenário cinematográfico sobre uma nova maneira de realizar cinema, ainda que essa atitude não fosse consensual entre aqueles que discutiam o destino da cultura artística no país.

Por fim, buscamos aqui nos conectar com o conceito de horizonte de expectativas, chave para a chamada "hermenêutica literária de Jauss" (1994). Conforme 
o autor, o modo de recuperar os atos de leitura de um texto artístico se funda na ideia de horizonte, isto é, na recuperação da pergunta para a qual o texto foi uma resposta, e ao recuperar a pergunta, recupera-se a história da recepção de que ele foi objeto.

Desse modo, podemos pensar que a contribuição do presente trabalho foi a de um esforço para recuperar o horizonte de recepção de Dona Flor, filme que se mostrou fundamental para as discussões sobre a concepção de um cinema nacional popular para o país. Se a crítica dos anos 1970 leu Dona Flor como um filme polêmico, sobretudo por sua estratégia de conciliação com o mercado, hoje essa disputa discursiva ainda se mantém atual, haja visto o debate frequente suscitado pela imprensa cinematográfica em torno das produções da Globo Filmes.

Os caminhos tomados por uma fatia do cinema brasileiro contemporâneo têm flertado com o modelo de produção de Dona Flor, particularmente as comédias populares. Não por acaso, estas, tal qual o filme de Barreto, vêm alcançando as principais bilheterias do país.

\section{Notas finais}

Em 2016, Dona Flor completou 40 anos, aniversário que mereceu destaque no Folha de S. Paulo e alusão ao fato de a crítica não ter sido favorável na sua estreia. Seu horizonte de recepção crítica mudou? Certamente sim, vez que ele hoje ocupa a 39a posição no ranking dos 100 melhores filmes brasileiros da Associação Brasileira de Críticos de Cinema (Abraccine), reforçando o quanto as convenções de leitura da crítica são marcadas por camadas de sentido acumuladas no tecido histórico que distingue a época.

Neste artigo, consideramos que a recepção de um filme deve ser compreendida dentro de seu horizonte histórico e estético, e Dona Flor certamente balançou as convenções estabelecidas, trazendo vestígios que apontavam para uma nova ordem que viria se consolidar no país décadas depois, no cenário contemporâneo. Os discursos produzidos sobre o filme, tanto os da imprensa internacional como dos críticos de cinema locais, afinavam-se no questionamento da proposta estéticomercadológica que circulava fortemente nas décadas de 1970 e 1980.

Embora houvesse exceções na crítica estrangeira, muitas opiniões se fizeram mais presentes na imprensa brasileira, já que era o momento de inflexão para o cinema nacional, que se configurou na ideia de "crise" do cinema moderno. Aqui os comentários dos críticos estavam de mãos dadas com os debates produzidos sobre a cena cultural do país. 
Convém salientar o conceito de poética histórica, de Bordwell (1991), para quem os significados atribuídos aos filmes são sempre construídos, tecidos no campo histórico, cultural e político. Dessa forma, Dona Flor não só põe a poética anterior em crise, apresentando um projeto estético diferenciado, como também é parte integrante de um cenário em que se tentava abrir novas formas de engajamento com o público, edificando perspectivas, ainda que relativamente descompromissadas, que convidassem o cinema brasileiro a inserir-se em um novo modelo de produção, calçado no pragmatismo das narrativas lineares, em personagens empáticos e na verossimilhança. Ademais, o conjunto de textos críticos tem forte poder de condicionamento interpretativo, haja vista a linguagem persuasiva integrante de sua função retórico-argumentativa. A significação construída pela crítica, influenciada pelo contexto que circunda esses discursos, convence e contamina a avaliação do leitor (e futuro espectador) e pode definir o modo de "ler" um filme.

Resta-nos dizer que essa investigação tentou iluminar os significados sóciohistóricos e culturais de alguns textos específicos, produzidos em circunstâncias e por leitores específicos, com a intenção de contribuir para o debate acerca da crítica de cinema como traço de recepção dos filmes.

Conforme Jauss (1979) e Staiger (2000), as condições históricas elucidam estratégias de interpretação e respostas afetivas dos leitores, aqui representados pelos críticos de cinema. Dona Flor teve uma recepção crítica impregnada por polêmicas da época, e a contaminação das tensões nos discursos tornava claro, na crítica estrangeira e sobretudo na brasileira, uma fissura e ao mesmo tempo uma autorreflexão sobre qual tipo de projeto seguir com o cinema brasileiro. Se a crítica estrangeira saudou o filme de Bruno Barreto qualificando-o como um "samba cinematográfico" e endossou a nostálgica ideia de "restauração" do cinema moderno, a crítica nacional levou adiante o salutar e necessário debate sobre modelos de produção que o cinema nacional popular assumiria a partir daquele momento.

\section{Referências}

ADAMATTI, M. M. Crítica de cinema e patrulha ideológica: o caso Xica da Silva de Carlos Diegues. In: FAMECOS, Porto Alegre, v. 23, n. 3, set./dez. 2016. Disponível em: <bit.ly/2I07RrZ>. Acesso em: 23 mar. 2018.

BAECQUE, A. Crítico de cinema e pesquisador francês Antoine de Baecque faz conferência em Porto Alegre no sábado. Entrevistador: Marcelo Perrone. Zero Hora, Porto Alegre, 6 nov. 2014. Disponível em: < https://goo.gl/SSooY9>. Acesso em: 7 nov. 2014.

BALLERINI, F. Cinema brasileiro no século 21: reflexões de cineastas, produtores, 
distribuidores, artistas, críticos e legisladores sobre os rumos da cinematografia nacional. São Paulo: Summus, 2012.

BORDWELL, D. Making meaning: inference and rhetoric in the interpretation of cinema. USA: Harvard University Press, 1991.

BORDWELL, D.; STAIGER, J.; THOMPSON, K. The classical Hollywood cinema: film style and the mode of production to 1960. New York: Columbia University, 1986. DONA FLOR E SEUS DOIS MARIDOS. Filme Cultura, Rio de Janeiro, v. 4, p. 242-253, 2010.

GOMES, R. O cinema brasileiro em Portugal: uma análise crítica de filmes brasileiros. Salvador: Edufba, 2015.

FIGUEIRÔA, A. Cinema Novo: a onda do jovem cinema e sua recepção na França. São Paulo: Papirus, 2004.

JAUSS, H. R. Estética da recepção: colocações gerais. In: LIMA, Luiz Costa. A literatura e o leitor: textos de estética da recepção. Rio de Janeiro: Paz e Terra, 1979. p. 43-61.

. A história da literatura como provocação à teoria literária. São Paulo: Ática, 1994.

RAMOS, F. (Org.). História do cinema brasileiro. São Paulo: Art, 1987.

SILVA, E. Há 40 anos, "Dona Flor e seus dois maridos" estreava e levava milhões às salas de cinema. Folha de S. Paulo, São Paulo, 22 nov. 2016. Disponível em: <bit. ly/2pzDodh>. Acesso em: 22 nov. 2016.

STAIGER, J. Interpreting films: studies in the historical reception of American cinema. Princeton: Princeton University Press, 1992.

Perverse spectators: the practices of film reception. New York: New York University Press, 2000.

Media reception studies. New York: New York University Press, 2005.

STAM, R. Introdução à teoria do cinema. São Paulo: Papirus, 2003.

\section{Referências audiovisuais}

A DAMA do Lotação. Neville de Almeida, Brasil, 1978.

DONA Flor e seus dois maridos. Beto Barreto, Brasil, 1976.

XICA da Silva. Cacá Diegues, Brasil, 1976.

submetido em: 21 set. 2017 | aprovado em: 29 dez. 2017 